\title{
Gene-expression profiling elucidates molecular signaling networks that can be therapeutically targeted in vestibular schwannoma
}

\author{
Laboratory investigation
}

\author{
*Sameer Agnihotri, Ph.D., ${ }^{1}$ Isabel Gugel, M.D., ${ }^{2}$ Marc Remke, M.D., ${ }^{1,3,4}$ \\ Antje Bornemann, M.D., Ph.D., ${ }^{5}$ Georgios Pantazis, M.D., ${ }^{6}$ Stephen C. Mack, B.Sc., $, 1,3,4$ \\ David Shit, M.Sc., ${ }^{1,3,4}$ Sanjay K. Singh, Ph.D., ${ }^{1}$ Nesrin Sabha, B.S., ${ }^{1}$ \\ Michael D. TaYlor, M.D., Ph.D., ${ }^{1,3,4}$ Marcos Tatagiba, M.D., Ph.D., 2 \\ Gelareh Zadeh, M.D., Ph.D., ${ }^{7}$ ANd Boris Krischek, M.D., Ph.D. ${ }^{2,8}$
}

${ }^{1}$ Arthur \& Sonia Labatt Brain Tumour Research Centre and ${ }^{3}$ Program in Developmental \& Stem Cell Biology, The Hospital for Sick Children, Toronto; ${ }^{4}$ Department of Laboratory Medicine \& Pathobiology, University of Toronto; ${ }^{7}$ Division of Neurosurgery, Toronto Western Hospital, University of Toronto, Ontario, Canada; Departments of ${ }^{2}$ Neurosurgery and ${ }^{5}$ Neuropathology, University of Tübingen; ${ }^{6}$ Department of Neuropathology, University of Marburg; and ${ }^{8}$ Department of Neurosurgery, University of Cologne, Germany

Object. Vestibular schwannomas (VS) are common benign tumors of the vestibular nerve that cause significant morbidity. The current treatment strategies for VS include surgery or radiation, with each treatment option having associated complications and side effects. The transcriptional landscape of schwannoma remains largely unknown.

Methods. In this study the authors performed gene-expression profiling of 49 schwannomas and 7 normal control vestibular nerves to identify tumor-specific gene-expression patterns. They also interrogated whether schwannomas comprise several molecular subtypes using several transcription-based clustering strategies. The authors also performed in vitro experiments testing therapeutic inhibitors of over-activated pathways in a schwannoma cell line, namely the PI3K/AKT/mTOR pathway.

Results. The authors identified over 4000 differentially expressed genes between controls and schwannomas with network analysis, uncovering proliferation and anti-apoptotic pathways previously not implicated in VS. Furthermore, using several distinct clustering technologies, they could not reproducibly identify distinct VS subtypes or significant differences between sporadic and germline NF2-associated schwannomas, suggesting that they are highly similar entities. The authors identified overexpression of PI3K/AKT/mTOR signaling networks in their geneexpression study and evaluated this pathway for therapeutic targeting. Testing the compounds BEZ235 and PKI-587, both novel dual inhibitors of PI3K and mTOR, attenuated tumor growth in a preclinical cell line model of schwannoma (HEI-293). In vitro findings demonstrated that pharmacological inhibition of the PI3K/AKT/mTOR pathway with next-generation compounds led to decreased cell viability and increased cell death.

Conclusions. These findings implicate aberrant activation of the PI3K/AKT/mTOR pathway as a molecular mechanism of pathogenesis in VS and suggest inhibition of this pathway as a potential treatment strategy.

(http://thejns.org/doi/abs/10.3171/2014.6.JNS131433)

\section{KEY WORDS - vestibular schwannoma PI3K-AKT inhibitors • therapeutics}

- molecular profiling -

$\mathrm{V}$

ESTIBULAR schwannomas (VSs) are tumors that arise from the Schwann cell sheath of the vestibulocochlear nerve with an incidence of 0.7 per 100,000 .

\footnotetext{
Abbreviations used in this paper: $\mathrm{c}-\mathrm{KIT}=$ stem cell factor receptor; $\mathrm{ERM}=$ ezrin, moesin, and radixin; $\mathrm{MAD}=$ median absolute deviation; miRNA = micro-RNA; NF2 = neurofibromatosis Type 2 ; $\mathrm{NMF}=$ nonnegative matrix factorization; $\mathrm{PCA}=$ principal component analysis; $\mathrm{PDGF}=$ platelet-derived growth factor; $\mathrm{PDGFR}=$ PDGF receptor; ROS = reactive oxygen species; VS = vestibular schwannoma.

* Drs. Zadeh and Krischek contributed equally to this work.
}

These tumors are usually unilateral, although in 5\%-10\% of cases, they are bilateral and are associated with the cancer predisposition syndrome neurofibromatosis Type 2 (NF2). Despite surgical excision and radiosurgery, VS can cause significant morbidity through compression of the surrounding structures as well as obstruction of cerebrospinal fluid flow.,19 Possible permanent neurological deficits due to VS include hearing loss, tinnitus, vertigo, and facial palsy. In addition, for a distinct population of patients with NF2, repeat surgery and radiosurgery for primary or recurrent tumors are not reasonable options, and no additional therapeutic options are currently available. 
To date, the underlying biology driving schwannoma tumorigenesis is poorly understood. The most characterized gene associated with schwannoma is neurofibromatosis 2 (NF2). This tumor suppressor gene, located on chromosome 22 at $22 \mathrm{q} 12.2$, encodes the protein merlin, ${ }^{37}$ also called schwannomin, ${ }^{29}$ which belongs to the ezrin, moesin, and radixin (ERM) family of proteins, which associate the actin cytoskeleton with the cell membrane. ${ }^{6}$ Schwann cell-specific knockout of NF2 in mice leads to initiation of schwannomas with similarities to VS in patients with NF2. Mechanistically, loss of NF2 has been linked to aberrant activation of signaling pathways involving cell survival, growth, and proliferation, namely the PI3K/AKT/mTOR ${ }^{5,15,16,28}$ and ERK1/2 signaling pathways. ${ }^{1}$ It has been reported that loss of NF2 by deletion, mutation, or loss of protein or transcript occurs in $66 \%$ to $100 \%$ of all sporadic schwannomas. ${ }^{13,34}$ Additionally, receptor tyrosine kinases such as stem cell factor receptor (c-KIT) and platelet-derived growth factor receptor (PDGFR)- $\alpha$ and $-\beta$, have been demonstrated to be overexpressed and overactivated in sporadic and NF2-associated peripheral and vestibular schwannomas. ${ }^{22,30}$ Preclinical targeting of c-KIT, PDGFR- $\alpha$, and PDGFR- $\beta$ with imatinib and nilotinib using the immortalized $N F 2$-null VS cell line HEI-193 demonstrated that receptor tyrosine kinase (RTK) inhibition increased apoptosis, and cell cycle arrest decreased anchorage-independent growth. ${ }^{22,30}$

The transcriptome of schwannoma remains poorly understood, as inappropriate control tissues or insufficient sample numbers were used in the few published studies investigating gene expression in this condition. Thus, identification of novel recurring alterations in schwannoma is limited leading to a poor fundamental understanding of core signaling pathways that are activated, which may serve as therapeutic targets. To address this issue, we conducted the largest VS transcriptome study to date, comparing gene-expression profiles of 49 schwannomas and 7 normal control vestibular nerve tissue samples, the most appropriate control tissue, to identify differentially expressed genes. To our knowledge, this is the first genome-wide microarray expression study that compares the tumor tissue to the tissue of origin, the vestibular nerve. We performed several transcriptional profiling techniques, both supervised and unsupervised, to identify gene-expression patterns unique to VS. We demonstrated that germline-associated and sporadic schwannomas are molecularly homogeneous. Notably, we revealed aberrant activation of the phosphoinositide 3-kinase-AKT-mammalian target of rapamycin (PI3K/AKT/mTOR) signaling networks and investigated their potential as therapeutic targets with novel dual specificity inhibitors.

\section{Methods}

\section{Clinical and Patient Sample Information}

Tissue samples were collected during the surgical excision of tumors from 36 patients with sporadic VS and 13 patients with a history of NF2. All samples were collected before radiation or any other adjuvant treatment. Seven specimens of vestibular nerve tissue were obtained post mortem and used as controls. Clinical samples and data were used in accordance with research ethics board approval from the University of Tübingen, Germany. Informed consent was obtained from all patients in this study. Use of samples for this study was approved by the Ethics Board of the Medical Faculty and University Hospital of Tübingen.

\section{Gene-Expression Analysis}

Forty-nine VS samples were analyzed on the Affymetrix Human Genome U219 (HG-U219) array. Sample library preparation, hybridization, and quality control were performed according to Affymetrix's recommended protocols. CEL files were imported into Affymetrix Expression Console (Version 1.1) and gene level analysis (CORE content) was performed. Arrays were quantile normalized (sketch) and summarized using the PLIER (Probe Logarithmic Intensity Error) algorithm with PMGCBG background correction. Probesets were annotated according to the human genome build HG19 (GRCh37).

\section{Clustering Analysis}

To detect molecular substructures within tumor samples we used nonnegative matrix factorization (NMF), $\mathrm{K}$-means, and hierarchical clustering with agglomerative average linkage as our method for consensus clustering (R package: ConsensusClusterPlus). ${ }^{40}$ For unsupervised clustering, we selected $1000-5000$ probe-sets exhibiting the largest median absolute deviation (MAD). Clustering was performed over 1000 iterations at a subsampling ratio of 0.8. SigClust was used to compute significance tests on the identified clusters in a pairwise fashion $(\mathrm{R}$ package: sigclust).$^{39}$ Silhouette analysis was performed to identify quality and strength of clusters (R package: cluster). ${ }^{17}$ Principal component analysis was performed using Genepattern and PARTEK software including the same 1000 genes or 2500 variable genes identified by MAD.

\section{Western Blotting}

HEI-193 cells were lysed in PLC lysis buffer (50 mM HEPES [pH 7.5], $150 \mathrm{mM} \mathrm{NaCl}, 10 \%$ glycerol, $0.1 \%$ Triton-X, $1.5 \mathrm{mM} \mathrm{MgCl} 2,1 \mathrm{mM}$ EGTA, $10 \mathrm{mM} \mathrm{NaP}_{2} \mathrm{O}_{7}$, $100 \mathrm{mM} \mathrm{NaF}$, and $1 \mathrm{mM} \mathrm{Na} \mathrm{VO}_{4}$ ) containing protease and phosphatase inhibitors (Sigma-Aldrich). Protein concentration was determined using the BCA (bicinchoninic acid) assay (Thermo Fisher Scientific). Thirty micrograms of protein lysate were loaded into $10 \%$ or 12\% SDS-PAGE gels. Proteins were then transferred onto PVDF membrane (NEN Research Products) using a semidry transfer apparatus (Bio-Rad Laboratories). Membranes were blocked in 5\% milk TBST or 5\% BSA TBST per the manufacturer's instructions for an hour and probed for varying proteins at $4^{\circ} \mathrm{C}$ overnight. After incubation, membranes were washed in TBST (three 10-minute washes) and incubated with horseradish peroxidaseconjugated antibodies against the species the primary antibody was raised against (Bio-Rad Laboratories). Protein detection and quantification was performed by using Chemiluminescence Reagent Plus (PerkinElmer) using the Alpha Imager HP imaging system for nonsaturated densitometric analysis followed by exposure to x-ray film 
for band visualization. Antibodies were purchased from Cell Signaling Technologies and used according to the manufacturer's directions: phospho-AKT Ser473 (catalog no. 4058), phospho-AKT Thr 308 (catalog no. 244F9), AKT (catalog no. 4691), phospho-p70 S6 kinase Ser371 (catalog no. 9208), p70-S6 kinase (catalog no. 2708).

\section{Cell Culture and Inhibitors}

HEI-193 cells were obtained from American Type Culture Collection (ATCC). The cells were grown in DMEM supplemented with $10 \% \mathrm{FBS}$ at $37^{\circ} \mathrm{C}$ in a $95 \%$ air $/ 5 \% \mathrm{CO}_{2}$ atmosphere. BEZ235 and PKI-587 were purchased from Selleck Chemicals and dissolved in DMSO (vehicle).

\section{Proliferation Assay}

Proliferation was measured using the Cell Proliferation ELISA, BrdU (chemiluminescent) assay (Roche Pharmaceuticals), performed as previously described. Briefly, cells were fixed and stained with anti-BrdU-POD antibody. Immune complexes and reactions were quantified using a multi-well luminometer.

\section{Apoptosis Assay}

Caspase 3/7 activity levels were measured 24-48 hours after drug treatment using the Apo-One Homogeneous Caspase 3/7 assay (Promega Corp.) as previously described..$^{30}$

\section{Colony-Forming Assay}

Briefly, 500 HEI-193 cells were plated in 6-well plates. Cells were grown in the presence of vehicle or BEZ235 or PKI-587 at $10 \mathrm{nM}$ and $100 \mathrm{nM}$. Colonies were stained with crystal violet and counted on Days 10 and 14.

\section{Statistical Analysis}

All experiments were performed in triplicate with mean and standard error of the mean reported where appropriate. Analysis of variance (ANOVA) was conducted for multigroup comparisons followed by a post-hoc Dunnett's test (groups compared with one control group) or post-hoc Tukey (to identify differences among groups). Where appropriate, direct comparisons were conducted using an unpaired 2-tailed Student t-test. Significance was defined as $\mathrm{p}<0.05$.

\section{Results}

Identification of Differentially Expressed Genes in Schwannoma Versus Normal Schwann Cells and Aberrant Signaling Networks in Schwannoma

To interrogate differentially expressed genes between normal Schwann cells, the putative cell of origin, and tumor, we conducted gene-expression profiling using the Affymetrix U219 microarray platform. We compared 7 vestibular nerve samples to $49 \mathrm{VS}$ specimens (13 from known NF2-associated cases and 36 from sporadic VS cases). Using Bonferroni corrected t-tests and significance analysis of microarray (SAM), we identified over 4000 expressed probe-sets representing 4241 genes with a minimum of 2 -fold change, a $\mathrm{p}$ value less than 0.05 , and a q value (false discovery rate) less than $0.1 \%$ (Supplemental Table 1). A total of 1412 genes were downregulated compared with normal tissue, and 2829 were upregulated (Fig. 1A). To identify novel gene networks and pathways that may be altered in VS, we performed gene pattern enrichment analysis and ingenuity pathway analysis using the differentially expressed transcripts. Cell proliferation and enrichment of antiapoptotic pathways were the most significantly represented cell functions in VS, with cell death, microtubule stability, and cell cycle inhibition significantly downregulated (Fig. 1B and C, p < 0.05). Furthermore, significantly upregulated signaling pathways included known alterations in VS, such as PI3K signaling and mTOR signaling, and other cancer signaling pathways, including RAC signaling, CDC42 signaling, and amyloid processing (Fig. 1D, $\mathrm{p}<0.05)$. Micro-RNA processing, reactive oxygen species (ROS) scavenging, and MYCN signaling were significantly downregulated (Fig. 1E, p < 0.05). Enrichment map pathway analysis was performed to illustrate that these aberrant signaling pathways are interconnected and that genes with differential expression in our analysis fit into multiple signaling nodes, with PI3K signaling and mTOR pathways having the highest significance (Fig. 1E, $\mathrm{p}<0.05$ ).

\section{Schwannomas Constitute a Molecularly Homogeneous Entity}

Molecular profiling of histologically indistinguishable tumors has revealed a great variety of tumor heterogeneity at the genetic, epigenetic, and transcript levels for several central nervous system cancers. ${ }^{23,24,27,39,41}$ Thus, we aimed to elucidate the molecular complexity within our VS samples. Using the median absolute deviation (MAD), we selected the 1000 most variable genes in our dataset for consensus clustering using NMF analysis testing for 2-8 subgroups (Fig. 2A). Despite varying the initial number of input genes $(1500,2500,5000$, Fig. 2B-D), we consistently found 2 subgroups as defined by the highest cophenetic coefficient value. However, these subgroups were not stable, as varying gene number altered the size of the 2 groups and resulted in samples switching groups (Fig. 2A-D). Furthermore, the cophenetic coefficient values were below 0.9 , demonstrating poor group strength (Fig. 2A-D). Using an additional distinct clustering technology, consensus hierarchical clustering, we inconsistently identified 2 or 3 subgroups despite varying gene numbers (data not shown). A third clustering algorithm, consensus k-means clustering also identified 2 putative subgroups (Fig. 2E and F). However, the low relative area under the curve $(<0.5)$ and heat maps demonstrated at 2 or 3 groups $(K=2$ or $K=3)$ that the subgrouping is poor and not stable (Fig. 2F). To examine whether these 2 subgroups were in fact artifact or biologically real, we employed SigClust and performed all pairwise comparisons between our NMF-defined subgroups using the most stable samples that never switched groups, with varying gene numbers. These putative subgroups were statistically insignificant (Fig. 2G, p > 0.99) and all samples were highly correlative to each other using unsupervised hierarchical clustering (Pearson correlation, $r=0.77$ ). Additionally, silhouette analysis of these 2 groups 


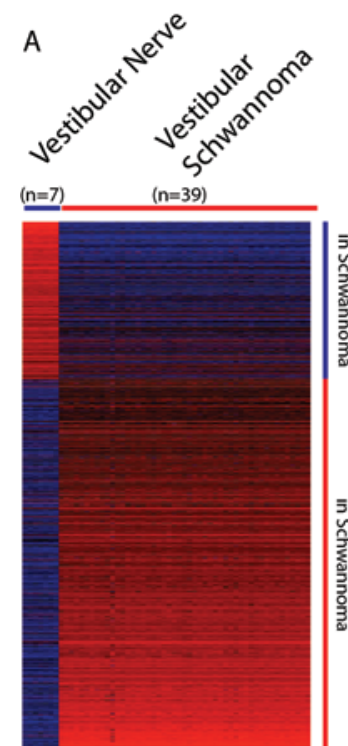

Z-Score RNA Expression

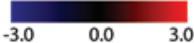

B

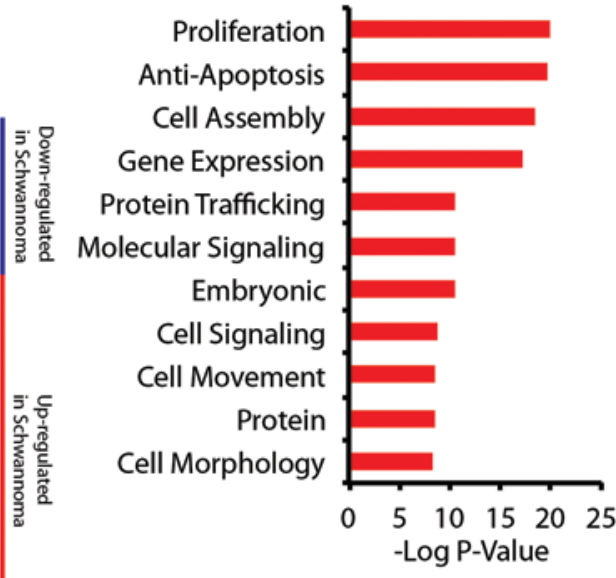

C

\section{Down-regulated Cell Functions}

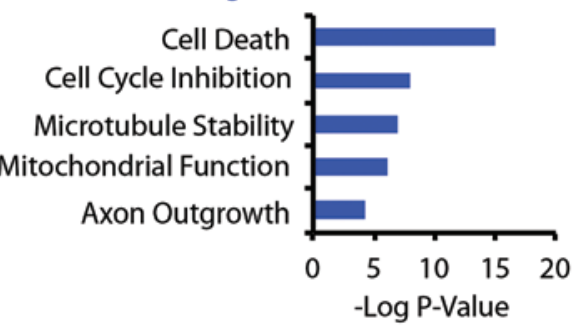

D

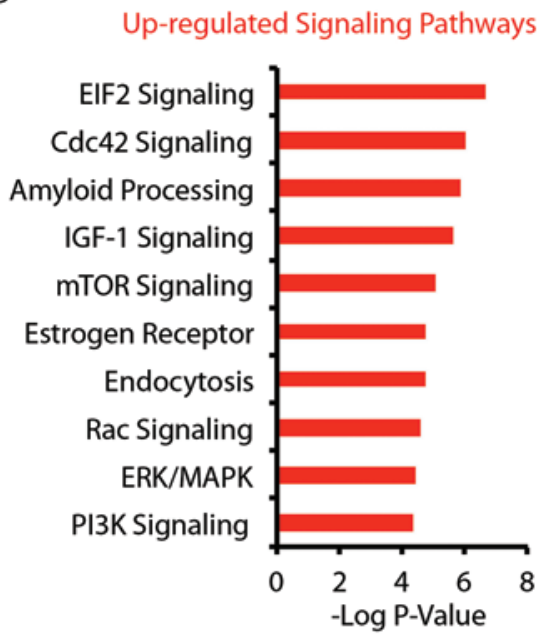

E

Down-regulated Signaling Pathways

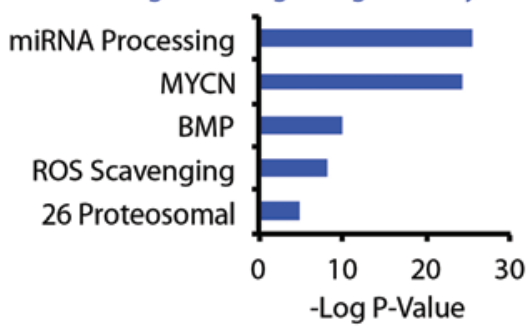

$\mathrm{F}$

Enrichment Map of Significant Pathway Interactions Upregulated in Schwannoma

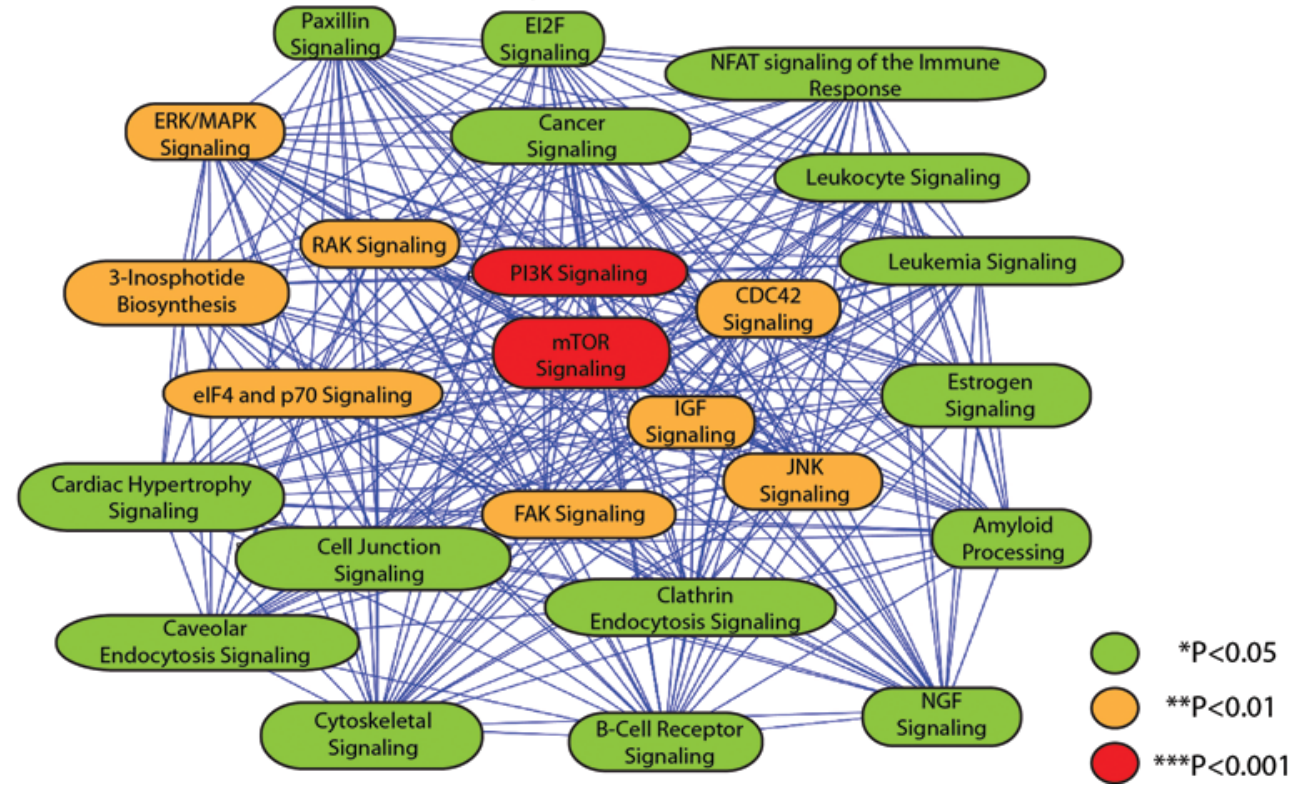

FIG. 1. Gene-expression analysis of VS versus normal vestibular nerve. A: Heat map identifying over 4998 significantly differentially expressed probes between normal vestibular nerve (Schwann cells) and VS. Significance was defined as a 2-fold change with a $p$ value $<0.05$ (Bonferroni corrected) and a false discovery rate $<0.1 \%$. B: Ingenuity pathway analysis of cell functions of genes enriched in VS. C: Ingenuity pathway analysis of cell functions decreased in VS. D: Ingenuity pathway analysis of signaling pathways of genes enriched in VS. E: Ingenuity pathway analysis of signaling pathways decreased in VS. F. Enrichment map of significant signaling network interactions $(p<0.05)$. PI3K and mTOR signaling pathways have the highest representation (yellow) and are predicted to directly activate other signaling pathways depicted in orange. 
A
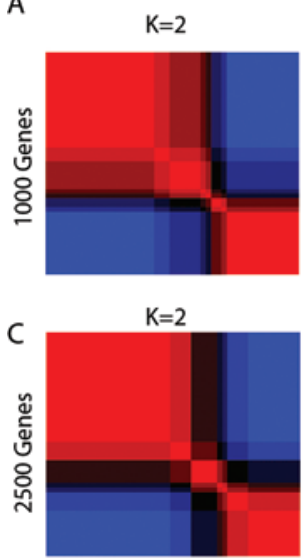

E

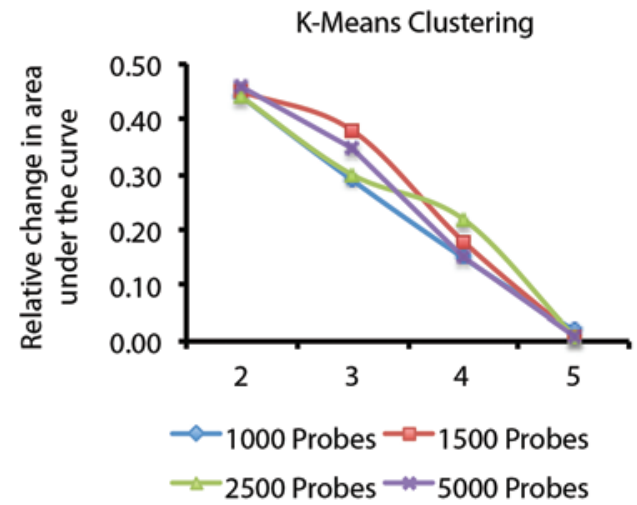

$\mathrm{H}$ Silhouette Width Analysis for $k=2$

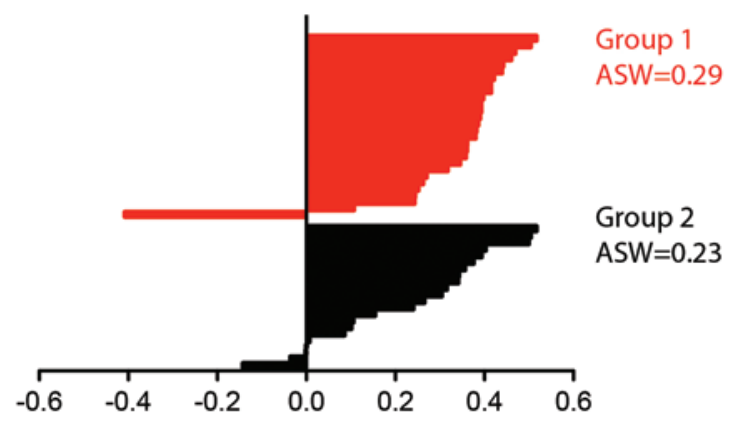

Silhouette Width
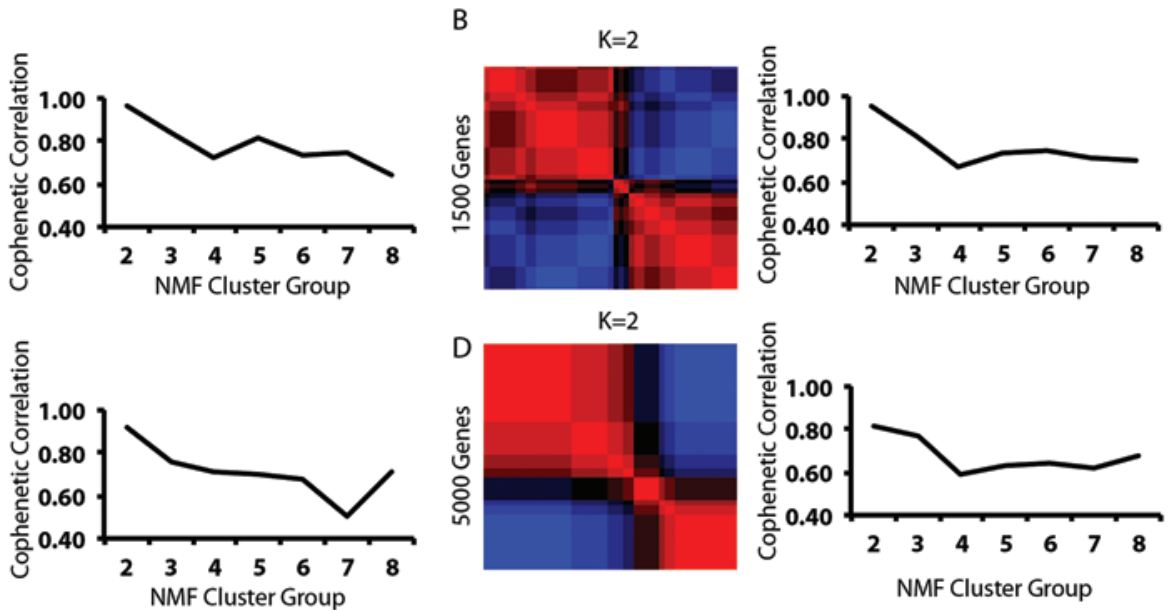

F

K-means Clustering $\mathrm{K}=2$

K-means Clustering K=2
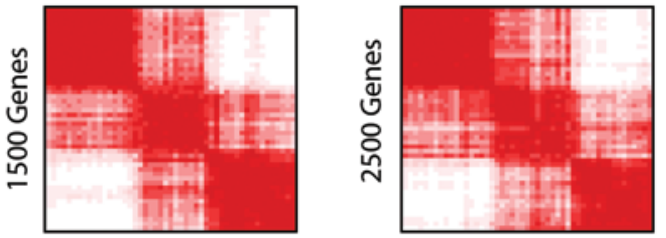

G

\begin{tabular}{ccc}
\multicolumn{3}{c}{ SigClust: p-values } \\
\hline & Group 1 & Group 2 \\
\hline Group 1 & -- & 1 \\
& & \\
Group 2 & 1 & --
\end{tabular}

I

Principle Component Analysis - 2500 genes

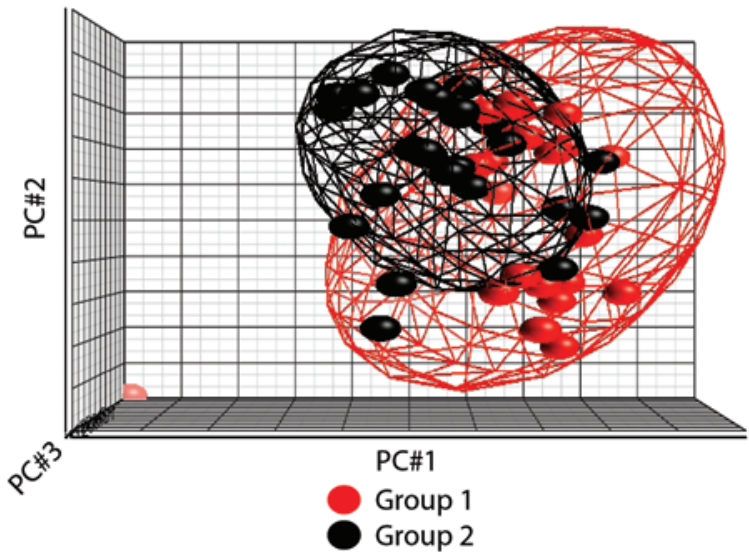

FIG. 2. Lack of robust clustering in VS. A-D: Heat maps of nonnegative matrix factorization (NMF) clustering of the 1000 , 1500,2500 , and 5000 most variable genes at $K=2$ (K denotes the number of clusters). Cophenetic correlation plot for each cluster $(\mathrm{K})$ where the highest value represents the strongest cluster. $\quad \mathrm{E}$ : Area under empirical cumulative distribution plots $(\mathrm{K}=2$ to $\mathrm{K}$ $=10$ ), generated from consensus k-means clustering of varying gene numbers. F: Consensus k-means clustering heat-maps at varying gene numbers showing nonrobust or impure clusters. G: Significance of NMF subgroup classifications determined by pairwise comparisons between all clusters using SigClust shows that the potential 2 clusters are not significantly different. H: Average silhouette width (ASW) analysis demonstrates that the ASW for both groups $<0.30$ may represent artificial grouping. I: Graphic illustration of global differences between the transcriptomes of the 49 schwannomas demonstrates that they are homogeneous as determined by principal component analysis (PCA). Tumors are represented as spheres, and ellipsoids are 2 standard deviations around each group. Overlap of ellipsoids demonstrated that the groups are not distinct from each other. 
produced nonrobust or low-average silhouette width areas of 0.29 and 0.23 , respectively, which indicates artificial or nonrobust cluster identification (Fig. 2H). Lastly, principal component analysis (PCA) with the same 1000 or 2500 most varying genes could not identify 2 or more significant molecular VS subgroups, as all samples grouped together and were significantly separated (Fig. 2I and data not shown). Collectively, in our dataset, VS are homogeneous and cannot be robustly subgrouped at the molecular level.

\section{Vestibular Schwannoma Subgroups Are Clinically Similar}

Although, the 2 molecular subgroups showed no statistically significant differences, we explored whether there could be clinical differences between the 2 clustering groups. We observed no difference in age, sex, tinnitus, vertigo, imbalance, or facial palsy between these 2 groups (Fig. 3A-F, p > 0.05). Furthermore, there were no significant differences among these groups based on MRI (data not shown). We next hypothesized that perhaps known NF2-associated (germline) VS cases could be distinct from sporadic cases. Principal component analysis (PCA) of the top 1000 or 2500 most variable genes could not identify significance between NF2-associated VS and sporadic VS (Fig. 3G and H). In summary, the molecular profile of the tumors as well as the clinical and radiological characteristics of the patients were homogeneous.

\section{Therapeutic Targeting of the PI3K/AKT/mTOR Signaling Axis Inhibits Schwannoma Growth}

At the transcript level, our VS samples regardless of their molecular characteristics or the clinical characteristics of the patients were homogeneous, leading us to hypothesize that they may share common features and pathways that could be used for targeted treatment. We observed that the mTOR and PI3K signaling pathways were consistently upregulated in our schwannomas (Fig. $1 \mathrm{D}, \mathrm{p}<0.001)$. Furthermore, we consistently observed upregulation of genes directly involved in activation of the $\mathrm{PI} 3 \mathrm{~K} / \mathrm{AKT} / \mathrm{mTOR}$ pathways and loss of negative regulators of this pathway, including NF2, PTEN, and TSC1/2, compared with expression in normal vestibular nerve (Fig. $4 \mathrm{~A}, \mathrm{p}<0.05)$.

Based on these observations, we selected BEZ235 and PKI-587, two novel dual ATP-competitive PI3K and mTOR inhibitors, to test on a cell line of VS, the NF2-null schwannoma cell line HEI-193. At $10 \mathrm{nM}$ and $100 \mathrm{nM}$, but not at $1 \mathrm{nM}$, both BEZ235 and PKI-587 significantly reduced cell viability over 5 days as measured by direct cell count compared with vehicle-treated cells (Fig. 4B and $C$, linear regression analysis, $p<0.05$ ). In addition, there was decreased proliferation as measured by $\mathrm{BrdU}$ incorporation on Day 3 for both BEZ235 and PKI-587 at $10 \mathrm{nM}$ and $100 \mathrm{nM}$ (Fig. 4D and E, p < 0.05).

BEZ235 and PKI-587 Inhibit Schwannoma Growth by Inducing Apoptosis, Reducing Anchorage-Independent Growth, and Reducing PI3K/AKT/mTOR Signaling

To assess the long-term impact of BEZ235 and PKI587, we performed a colony-forming assay. At $10 \mathrm{nM}$ and $100 \mathrm{nM}$, both inhibitors significantly reduced colony-form- ing units by Day 14, with no colonies observed at $100 \mathrm{nM}$ for both drugs (Fig. 5A and B, p < 0.0001). Consistent with reduced cell number, reduced proliferation, and reduced numbers of colony-forming units, both BEZ235 and PFI587 induced apoptosis at $10 \mathrm{nM}$ and $100 \mathrm{nM}$ in comparison with vehicle as measured by activated caspase $3 / 7$ activity (Fig. 5C, p < 0.05). We next investigated the specificity of our inhibitors, measuring phospho-AKT threonine 308 as a readout of PI3K signaling, phospho-AKT serine 473 as a readout of mTOR complex 2 signaling, and phopho-S6 kinase as a readout of mTOR complex 1 signaling. Application of $10 \mathrm{nM}$ BEZ235 significantly reduced pS6K at the protein level as quantified by chemiluminesce, while $10 \mathrm{nM}$ PKI-587 significantly reduced pS6K and pAKT serine 473 (Fig. 5D-F, p < 0.05) with no changes observed on pAKT threonine 308. At $100 \mathrm{nM}$, both BEZ235 and PKI-587 significantly reduced pAKT threonine 308 , pAKT serine 473 , and pSK6 (Fig. 5D-F, p < 0.05). In summary, BEZ235 and PKI-587 significantly reduce colony-forming units, induce apoptosis, and attenuate PI3K, AKT, and mTOR signaling in HEI-193 schwannoma cells.

\section{Discussion}

To our knowledge, this is the largest transcriptome analysis of VS. Moreover, our comparison of 49 VSs and 7 control vestibular nerve samples is the largest control tissue comparison of its kind and highly relevant, as Schwann cells from vestibular nerve are thought to be the cell of origin for VS. Our microarray analysis identified several significantly upregulated pathways in schwannomas, including CDC42, EIF2, and RAC signaling. Interestingly, these signaling pathways actively regulate RAS activity and cytoskeletal structure in several central nervous system tumors. These pathways have been implicated in schwannoma, and the results of our study, with its large number of samples analyzed, warrant investigating these pathways for novel therapeutic interventions. . $^{3,9,10,43}$ We also observed reduction of MYCN, BMP, and ROS signaling pathways. These pathways are underinvestigated and have not been implicated in schwannoma biology; further investigation into these signaling pathways may provide new insight into schwannoma formation. Additionally, our analysis identified several pathways previously characterized and implicated in schwannoma, such as IGF signaling, mTOR signaling, and PI3K signaling. ${ }^{2,514-16}$ Recent evidence has shown that several central nervous system tumors are characterized by great molecular heterogeneity and different clinical outcomes. ${ }^{23,24,26,35,39,41}$ Based on several distinct bioinformatic strategies, our data reveal highly similar gene-expression patterns in a molecularly homogeneous tumor entity. This is further supported by our observation that clustering results were not stable using different algorithms and gene lists.

We hypothesized that tumor samples from patients with germline-associated NF2 and sporadic schwannomas would be molecularly distinct. We observed no specific gene-expression differences between germline and sporadic VS, as evidenced by the lack of distinct clustering patterns and principal component analysis in the 
A

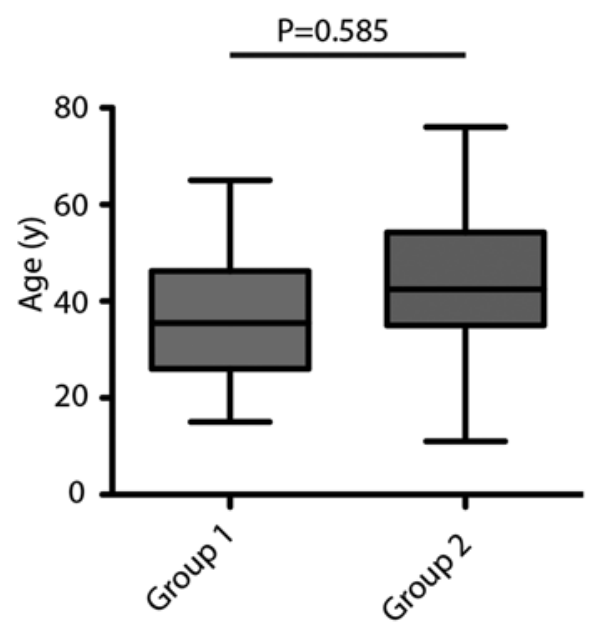

D

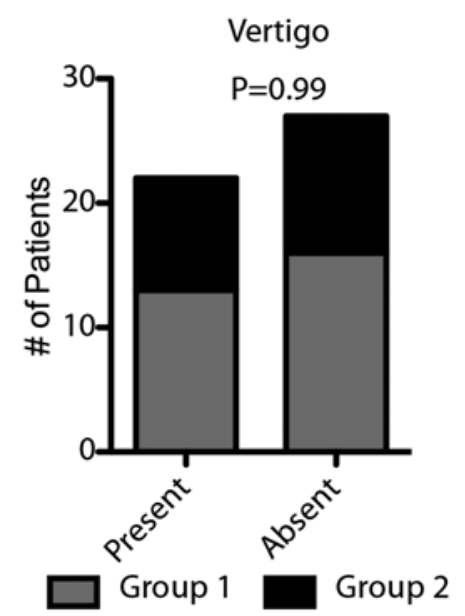

B

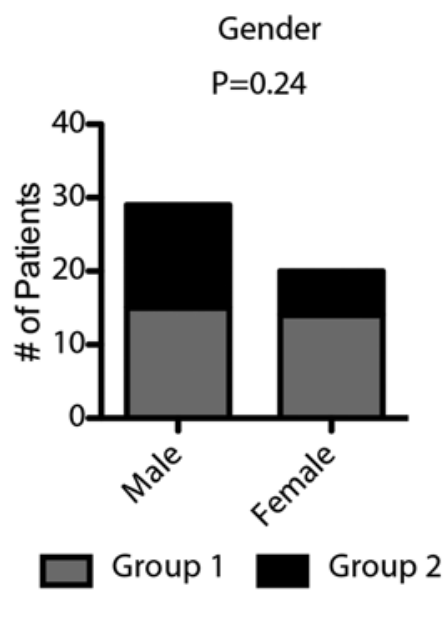

$\mathrm{E}$

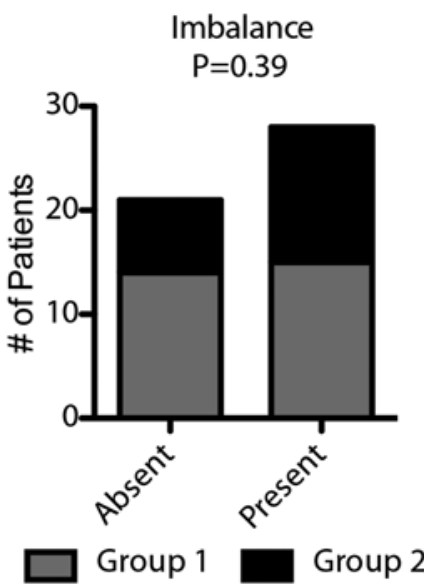

C

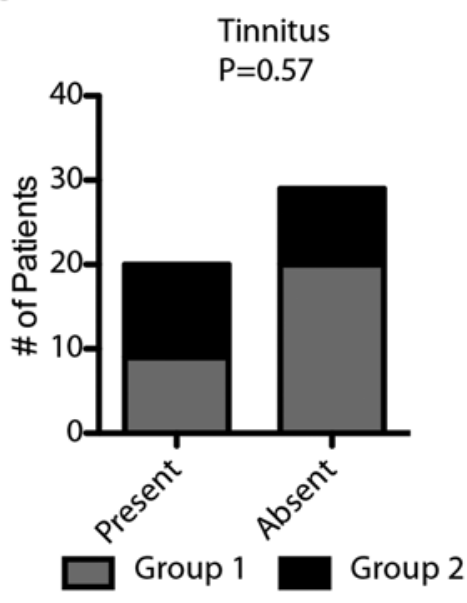

$\mathrm{F}$

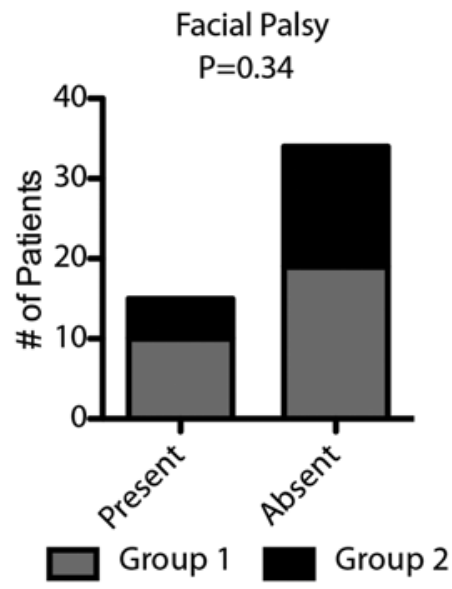

G Principle Component Analysis - 2500 genes
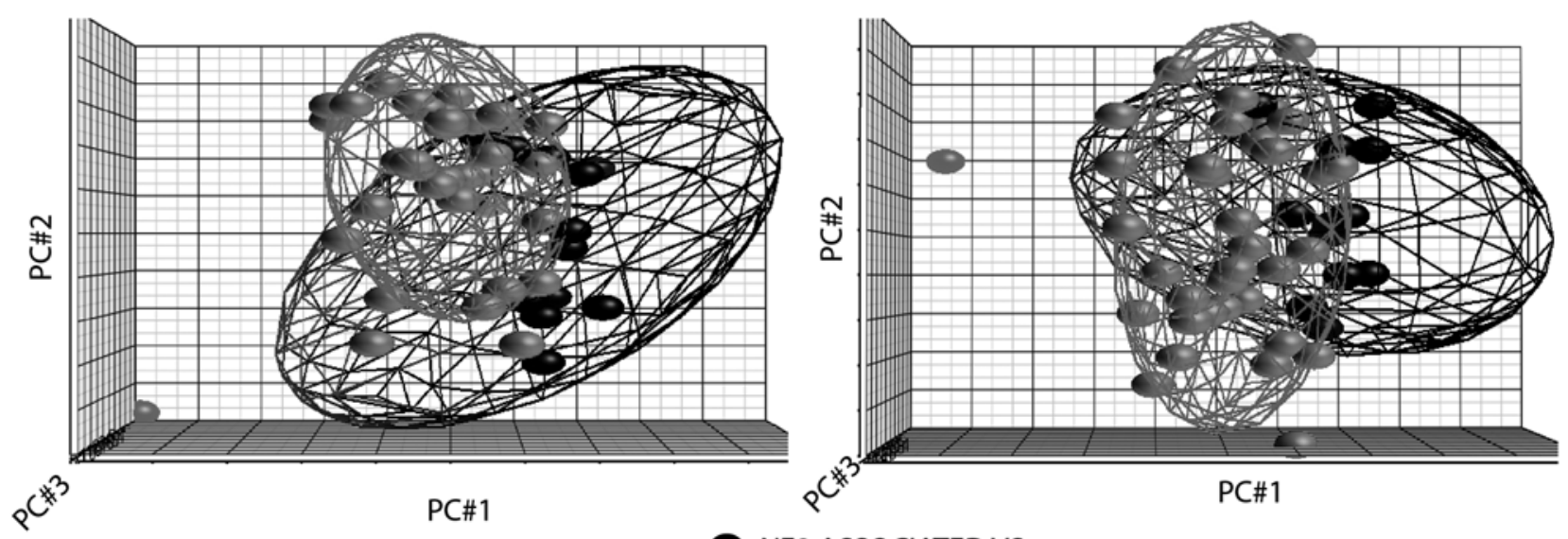

NF2 ASSOCIATEDVS SPORADICVS

FIG. 3. Lack of clinical differences in predicted VS groups. A-F: No significant differences were found between the 2 predicted VS patient groups with respect to age, gender (sex), tinnitus, vertigo, imbalance, or facial palsy. G and H: Graphic illustration of global differences between the transcriptomes of germline NF2-associated and sporadic VS using the 2500 and 1000 most variable expressed genes and PCA. Tumors are represented as spheres, and ellipsoids are 2 standard deviations around each group. Overlap of ellipsoids demonstrated that the groups are not distinct from each other. 
Gene-expression profiling in vestibular schwannoma

A PI3K-AKT-mTOR Signaling Pathway in Schwannoma

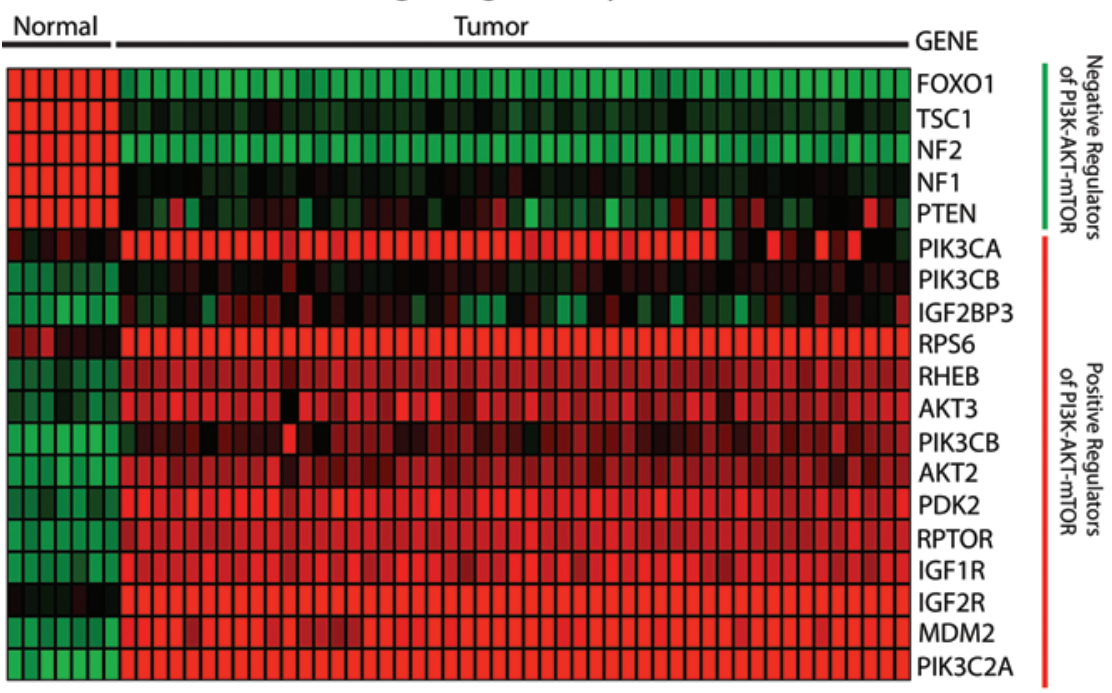

$0 \quad 5 \quad 8$

Min 2 Fold Change, ${ }^{* *} \mathrm{P}<0.001$

Log 2 RNA Expression

B

BEZ235

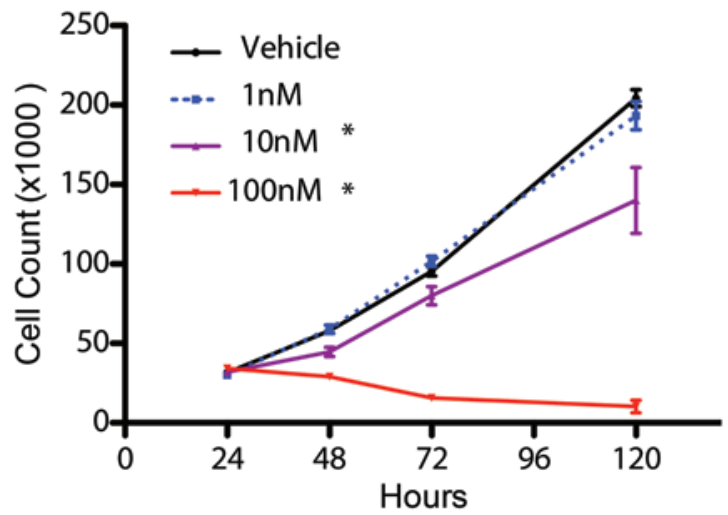

D

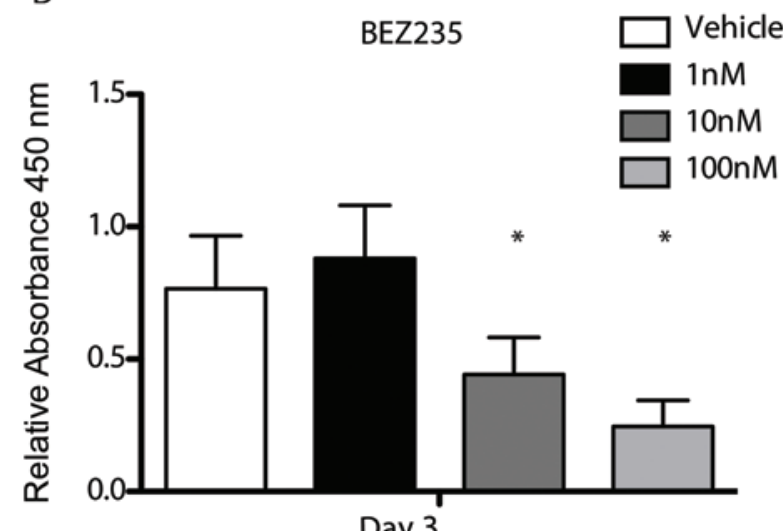

C

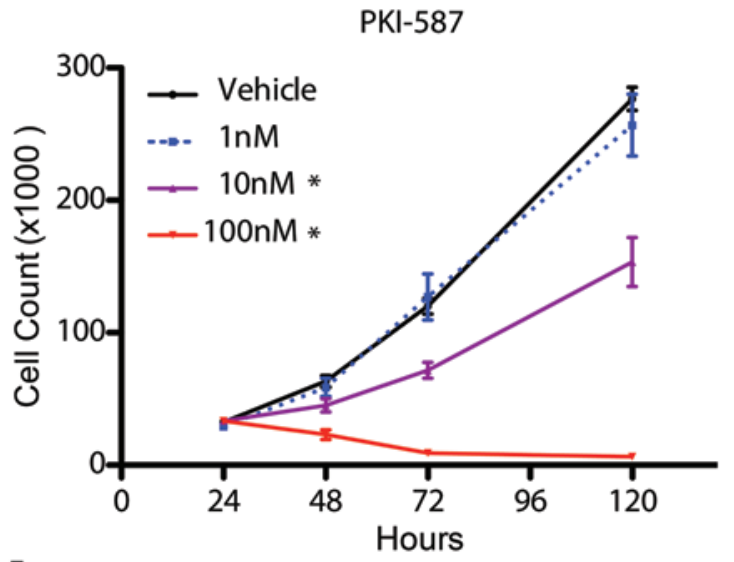

$\mathrm{E}$

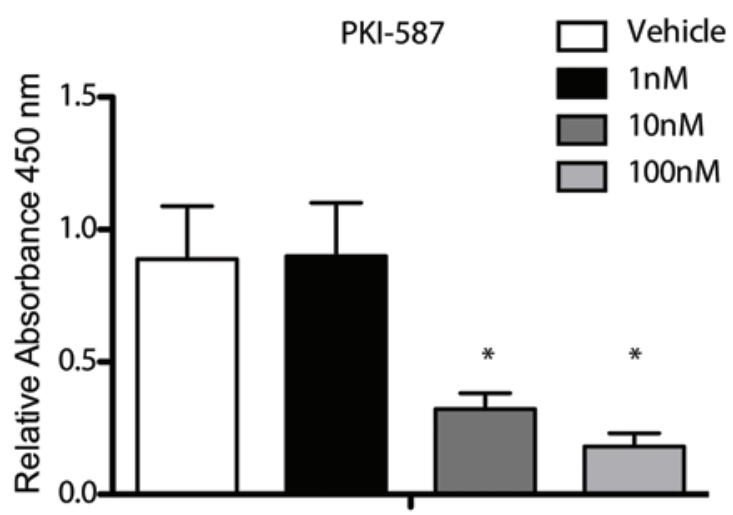

Day 3

FIG. 4. Validation of PI3K/AKT/mTOR signaling in VS. A: Heat map showing loss or gain of expression of negative regulators of the PI3K/AKT/mTOR pathway in schwannomas compared with normal vestibular nerve. B: Cell viability as measured by direct cell count of $\mathrm{HEl}-193$ schwannoma cells in the presence of varying BEZ235 concentrations over 5 days. C: Cell viability as measured by direct cell count of HEl-193 schwannoma cells in the presence of varying PKI-587 concentrations over 5 days. D and E: BrdU proliferation assay of HEl-193 cells measured at Day 3 after BEZ235 or PKI-587 treatment. * $p<0.05$. 
A

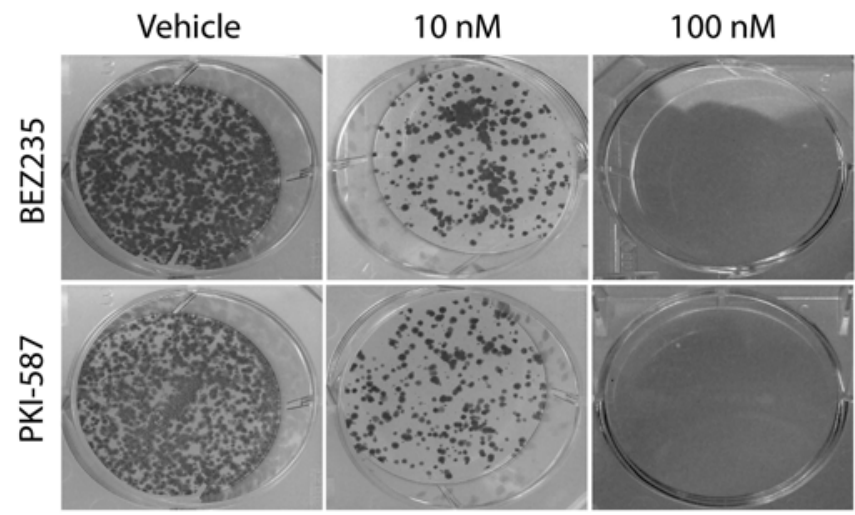

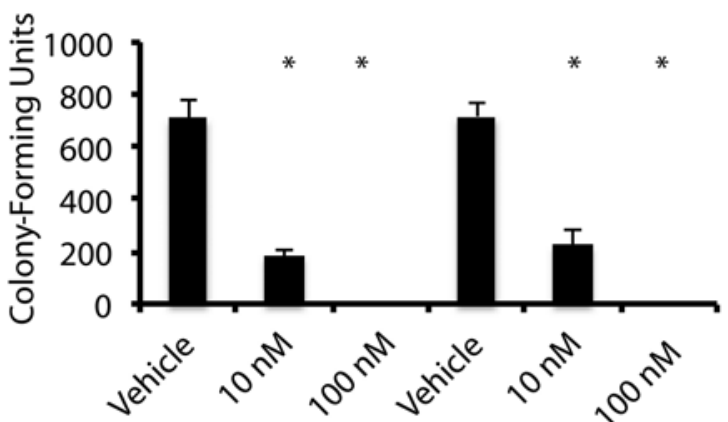

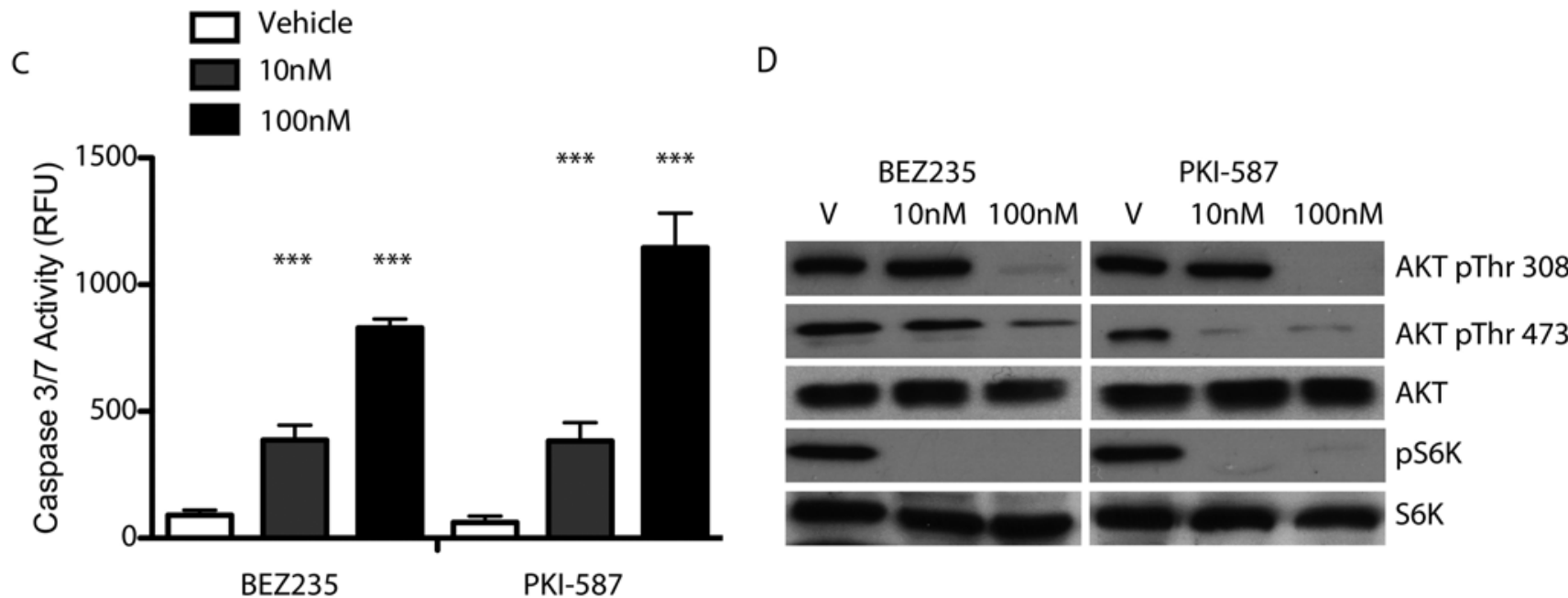

$\mathrm{E}$

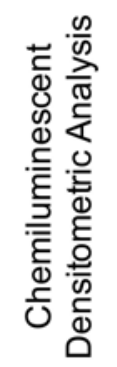

$\mathrm{F}$

PAKT T308/AKT

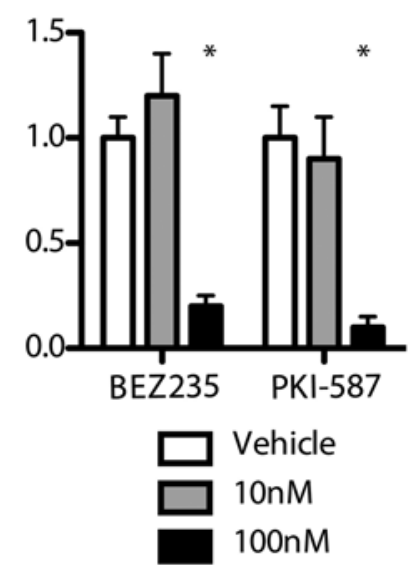

PAKT S473/AKT
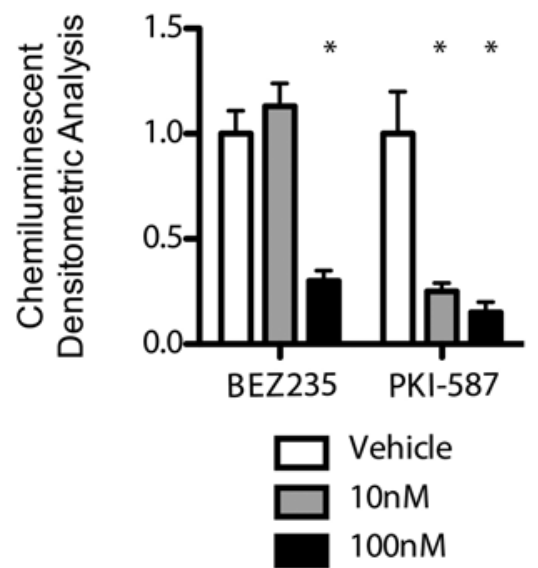

G
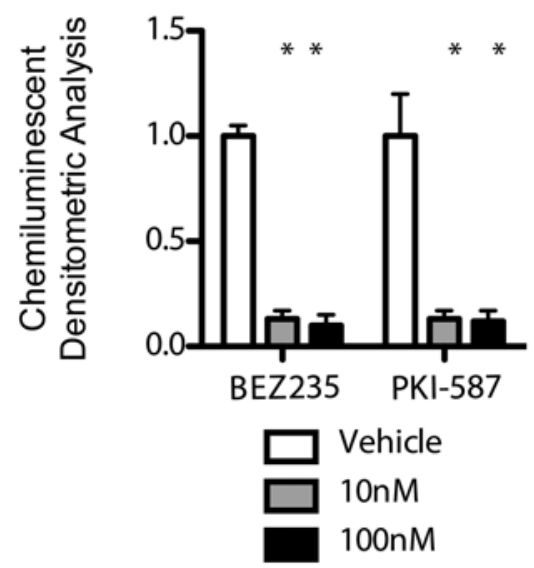

FIG. 5. Antitumor effects of dual PI3K and mTOR inhibitors BEZ235 and PKI-587 on an NF2-derived schwannoma cell line in vitro. A: Colony-forming assay of $\mathrm{HEl}$ schwannoma cell line at varying concentrations of BEZ235 and PKI-587. B: Quantification of A. C: Results of cleaved caspase activity assay demonstrating activation of cleaved caspase $3 / 7$ at $10 \mathrm{nM}$ and $100 \mathrm{nM}$ for both drugs compared with vehicle. RFU = relative fluorescence units. D: Western blot analysis demonstrating that BEZ235 and PKI-587 reduce phosphorylation of AKT and pS6K. E-G: Chemiluminescent quantification of phosphorylated AKT T308, phospho AKT S473, and phosphorylated pS6K. 


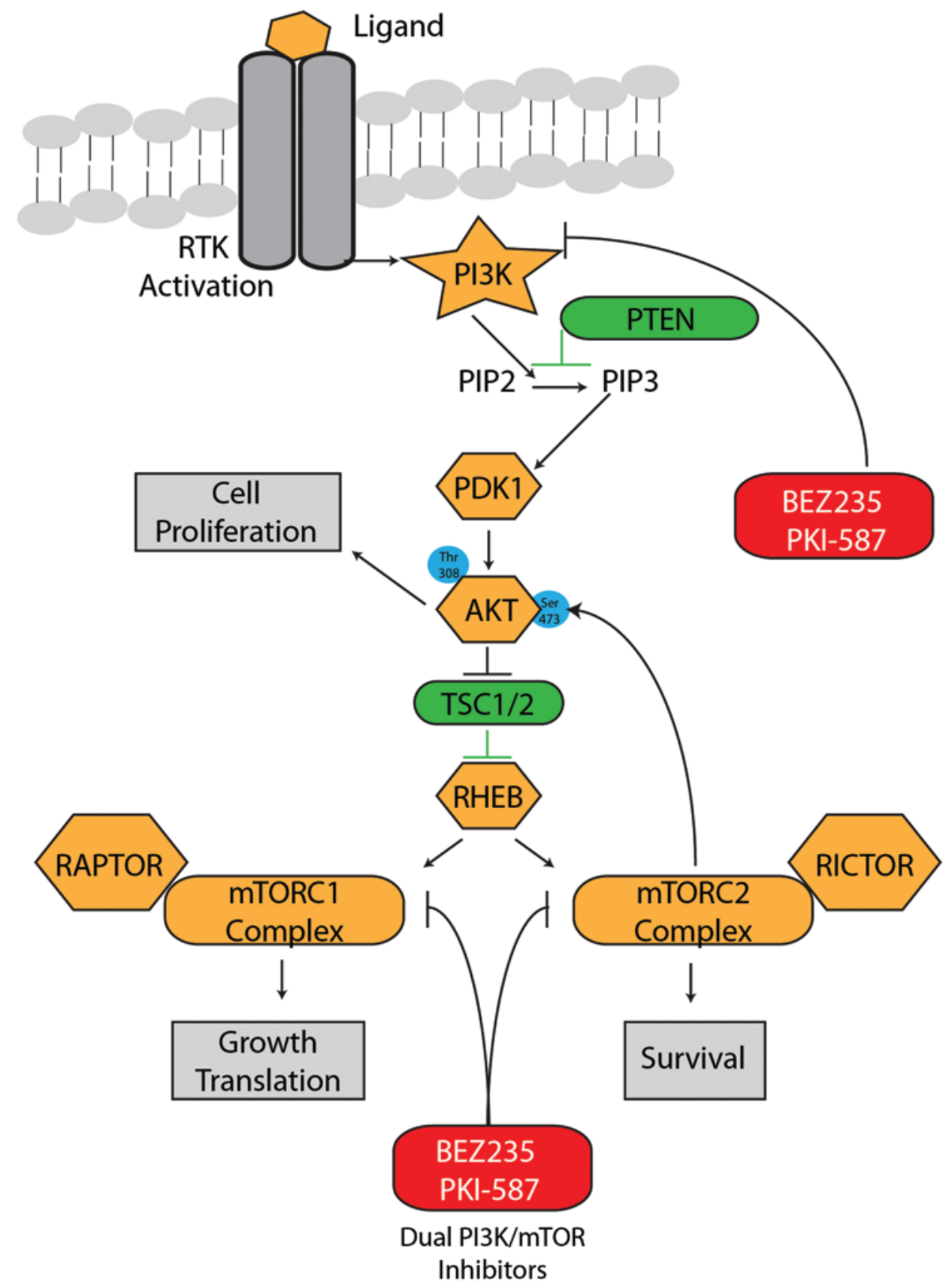

FIG. 6. The PI3K/AKT/mTOR signaling pathway and possible therapeutic targets for treatment of schwannoma. The dual PI3K and mTOR inhibitors BEZ235 and PKI-587 target multiple nodes of the PI3K/AKT/mTOR pathway, maximizing effect and reducing the possibilities of escape mechanisms, such as negative feedback or positive feedback loops, in comparison to the agents that act on single targets within this pathway. Thus dual target inhibitors have a greater chance of inhibiting cell growth and proliferation and inducing cell death.

tumors that we studied. Sporadic and germline VS are highly similar. Our observations lead us to postulate that VSs are molecularly homogeneous in our cohort and their clinical and radiological presentation is similar. The histopathological homogeneity of these tumors further supports this. Additionally, an independent study analyzing 31 schwannomas revealed no clear distinctions of germline and sporadic schwannomas. ${ }^{36}$ Given the observation that sporadic VS tissue harbors $60 \%-100 \%$ inactivation of $N F 2$, it is very likely that the molecular pathogenesis of both sporadic and germline schwannomas is similar. ${ }^{13,34}$

Targeted therapeutics and rational drug targeting strategies are of great interest in the treatment of schwannoma and other tumors. However, several targets that have been proposed were identified largely through candidate gene approaches, studies with small sample size, or identification of altered pathways from cell lines including nonhuman schwannoma cells. Our unbiased analysis identified 
that the most significant pathway upregulated in our 49 schwannomas was the PI3K/AKT/mTOR signaling pathway. Although the pathway has been previously implicated in schwannoma, our unbiased approach and large sample size further supports investigating this pathway for therapeutic targeting and novel treatments that may help reduce morbidity of schwannoma. The PI3K/AKT/mTOR signaling pathway has been implicated as one the most aberrant signaling pathways in several cancers, including glioblastoma, medulloblastoma, breast, lung, colon and prostate cancers. ${ }^{42}$ The Class I PI3Ks catalyze the mitogen-stimulated phosphorylation of phosphatidyl-inositol-4,5-bisphosphate (PtdIns[4,5]P2) to produce PtdIns(3,4,5)P3. This creates docking sites for several signaling proteins containing domains capable of binding to PtdIns(3,4,5)P3 or itself, ultimately leading to AKT and mTORC1 and mTORC2 activation. ${ }^{12,38}$ Phosphoinositide-dependent kinase (PDK1) and $\mathrm{Akt} / \mathrm{PKB}$ are several of the many signaling proteins that are recruited to the membrane and activated by binding to PtdIns(3,4,5)P3. PDK1 and the mammalian target of rapamycin (mTOR), acting in the rapamycin-insensitive TORC2 complex, activate AKT via phosphorylation of 2 key residues, T308 and S473, respectively. ${ }^{21,31,32,44}$ Rapamycin, an inhibitor of mTORC1, has been effective in both in vitro and in vivo models of several tumors, including schwannoma ${ }^{8,18}$ Conversely, inhibition of mTORC1 relieves a negative feedback on IRS1 in IGF1 signaling, ultimately leading to increased expression of phospho-AKT serine 473, a major survival marker., ${ }^{7,253}$ Therefore, multiple hits are required in effectively shutting down the PI3K/AKT/ mTOR pathway. To address this issue we selected 2 novel PI3K/mTOR inhibitors, BEZ235 and PKI-587, both of which bind and inhibit PI3K and mTOR. We hypothesized and observed that dual targeting of these interconnected pathways would yield the most effective method of targeting PI3K/AKT/mTOR signaling as summarized in Fig. 6. BEZ235 is in clinical trials for several cancers (https:// clinicaltrials.gov) and has recently been shown to be effective in schwannomas with minimal off-target effects. ${ }^{2}$ Collectively, our study validates and demonstrates that the $\mathrm{PI} 3 \mathrm{~K} / \mathrm{AKT} / \mathrm{mTOR}$ signaling pathway is highly upregulated in VS and offers an attractive therapeutic target for which clinical grade drug inhibitors exist. Although beyond the scope of this study, future work would involve conducting BEZ235 and PKI-587 studies on in vivo animal models of schwannoma $a^{11,20}$ and further exploring the genome of schwannoma by whole genome sequencing, copy number analysis, and methylation profiles to get a true representation of the VS. Furthermore, how VSs compare with and differ from spinal schwannomas is also of great biological and clinical interest.

\section{Conclusions}

The results of this study demonstrate that vestibular schwannomas are largely molecularly homogeneous at the transcript level and suggest that targeting of the PI3K/ AKT/mTOR pathway using novel dual inhibitors may provide new therapeutic interventions for a substantial majority of schwannoma patients.

\section{Acknowledgments}

We thank Dr. Michael Bonin and Dr. Michael Walter from the Department of Medical Genetics at the University of Tübingen for discussion and technical assistance.

\section{Disclosure}

The project was supported by a grant to Dr. Krischek from the Guido Fluri foundation. Dr. Zadeh was funded by grants from the Canadian Institute of Health Resources and the Terry Fox New Investigator Award.

Author contributions to the study and manuscript preparation include the following. Conception and design: Zadeh, Agnihotri, Krischek. Acquisition of data: Zadeh, Agnihotri, Gugel, Bornemann, Pantazis, Sabha. Analysis and interpretation of data: Zadeh, Agnihotri, Gugel, Remke, Mack, Shih, Singh, Krischek. Drafting the article: Zadeh, Agnihotri, Krischek. Critically revising the article: all authors. Reviewed submitted version of manuscript: all authors. Approved the final version of the manuscript on behalf of all authors: Zadeh. Statistical analysis: Zadeh, Agnihotri, Remke, Mack, Krischek. Administrative/technical/material support: Zadeh, Agnihotri, Sabha, Tatagiba. Study supervision: Zadeh, Agnihotri, Tatagiba, Krischek.

\section{Appendix}

This article contains an appendix that is available only in the online version of the article.

\section{References}

1. Ammoun S, Flaiz C, Ristic N, Schuldt J, Hanemann CO: Dissecting and targeting the growth factor-dependent and growth factor-independent extracellular signal-regulated kinase pathway in human schwannoma. Cancer Res 68:5236-5245, 2008

2. Ammoun S, Schmid MC, Ristic N, Zhou L, Hilton D, Ercolano E, et al: The role of insulin-like growth factors signaling in merlin-deficient human schwannomas. Glia 60:1721-1733, 2012

3. Ammoun S, Schmid MC, Zhou L, Ristic N, Ercolano E, Hilton DA, et al: Insulin-like growth factor-binding protein-1 (IGFBP-1) regulates human schwannoma proliferation, adhesion and survival. Oncogene 31:1710-1722, 2012

4. Balasubramaniam A, Shannon P, Hodaie M, Laperriere N, Michaels H, Guha A: Glioblastoma multiforme after stereotactic radiotherapy for acoustic neuroma: case report and review of the literature. Neuro Oncol 9:447-453, 2007

5. Blair KJ, Kiang A, Wang-Rodriguez J, Yu MA, Doherty JK, Ongkeko WM: EGF and bFGF promote invasion that is modulated by PI3/Akt kinase and Erk in vestibular schwannoma. Otol Neurotol 32:308-314, 2011

6. Bretscher A, Edwards K, Fehon RG: ERM proteins and merlin: integrators at the cell cortex. Nat Rev Mol Cell Biol 3:586-599, 2002

7. Carracedo A, Pandolfi PP: The PTEN-PI3K pathway: of feedbacks and cross-talks. Oncogene 27:5527-5541, 2008

8. Erdim R, Helvacioglu F, Gormez S, Karabay KO, Aytekin V: Two-year follow-up of sirolimus-eluting stents versus paclitaxel-eluting stents in acute myocardial infarction. Int J Angiol 21:53-58, 2012

9. Flaiz C, Chernoff J, Ammoun S, Peterson JR, Hanemann CO: PAK kinase regulates Rac GTPase and is a potential target in human schwannomas. Exp Neurol 218:137-144, 2009

10. Flaiz C, Utermark T, Parkinson DB, Poetsch A, Hanemann $\mathrm{CO}$ : Impaired intercellular adhesion and immature adherens junctions in merlin-deficient human primary schwannoma cells. Glia 56:506-515, 2008

11. Giovannini M, Robanus-Maandag E, van der Valk M, NiwaKawakita M, Abramowski V, Goutebroze L, et al: Conditional 
biallelic Nf2 mutation in the mouse promotes manifestations of human neurofibromatosis type 2. Genes Dev 14:1617-1630, 2000

12. Guertin DA, Sabatini DM: Defining the role of mTOR in cancer. Cancer Cell 12:9-22, 2007

13. Hadfield KD, Smith MJ, Urquhart JE, Wallace AJ, Bowers NL, King AT, et al: Rates of loss of heterozygosity and mitotic recombination in NF2 schwannomas, sporadic vestibular schwannomas and schwannomatosis schwannomas. Oncogene 29:6216-6221, 2010

14. Hilton DA, Ristic N, Hanemann CO: Activation of ERK, AKT and JNK signalling pathways in human schwannomas in situ. Histopathology 55:744-749, 2009

15. James MF, Han S, Polizzano C, Plotkin SR, Manning BD, Stemmer-Rachamimov AO, et al: NF2/merlin is a novel negative regulator of mTOR complex 1 , and activation of mTORC1 is associated with meningioma and schwannoma growth. Mol Cell Biol 29:4250-4261, 2009

16. James MF, Stivison E, Beauchamp R, Han S, Li H, Wallace MR, et al: Regulation of mTOR complex 2 signaling in neurofibromatosis 2-deficient target cell types. Mol Cancer Res 10: 649-659, 2012

17. Lovmar L, Ahlford A, Jonsson M, Syvänen AC: Silhouette scores for assessment of SNP genotype clusters. BMC Genomics 6:35, 2005

18. Malinowska IA, Lee N, Kumar V, Thiele EA, Franz DN, Ashwal S, et al: Similar trends in serum VEGF-D levels and kidney angiomyolipoma responses with longer duration sirolimus treatment in adults with tuberous sclerosis. PLoS ONE 8:e56199, 2013

19. Martin TP, Tzifa K, Kowalski C, Holder RL, Walsh R, Irving RM: Conservative versus primary surgical treatment of acoustic neuromas: a comparison of rates of facial nerve and hearing preservation. Clin Otolaryngol 33:228-235, 2008

20. Messerli SM, Tang Y, Giovannini M, Bronson R, Weissleder R, Breakefield XO: Detection of spontaneous schwannomas by MRI in a transgenic murine model of neurofibromatosis type 2. Neoplasia 4:501-509, 2002

21. Mora A, Komander D, van Aalten DM, Alessi DR: PDK1, the master regulator of AGC kinase signal transduction. Semin Cell Dev Biol 15:161-170, 2004

22. Mukherjee J, Kamnasaran D, Balasubramaniam A, Radovanovic I, Zadeh G, Kiehl TR, et al: Human schwannomas express activated platelet-derived growth factor receptors and ckit and are growth inhibited by Gleevec (Imatinib Mesylate). Cancer Res 69:5099-5107, 2009

23. Northcott PA, Korshunov A, Witt H, Hielscher T, Eberhart CG, Mack S, et al: Medulloblastoma comprises four distinct molecular variants. J Clin Oncol 29:1408-1414, 2011

24. Noushmehr H, Weisenberger DJ, Diefes K, Phillips HS, Pujara $\mathrm{K}$, Berman BP, et al: Identification of a $\mathrm{CpG}$ island methylator phenotype that defines a distinct subgroup of glioma. Cancer Cell 17:510-522, 2010

25. O'Reilly KE, Rojo F, She QB, Solit D, Mills GB, Smith D, et al: mTOR inhibition induces upstream receptor tyrosine kinase signaling and activates Akt. Cancer Res 66:1500-1508, 2006

26. Remke M, Hielscher T, Korshunov A, Northcott PA, Bender $\mathrm{S}$, Kool M, et al: FSTL5 is a marker of poor prognosis in nonWNT/non-SHH medulloblastoma. J Clin Oncol 29:38523861, 2011

27. Rickman DS, Bobek MP, Misek DE, Kuick R, Blaivas M, Kurnit DM, et al: Distinctive molecular profiles of high-grade and low-grade gliomas based on oligonucleotide microarray analysis. Cancer Res 61:6885-6891, 2001

28. Rong R, Tang X, Gutmann DH, Ye K: Neurofibromatosis 2 (NF2) tumor suppressor merlin inhibits phosphatidylinositol 3-kinase through binding to PIKE-L. Proc Natl Acad Sci U S A 101:18200-18205, 2004
29. Rouleau GA, Merel P, Lutchman M, Sanson M, Zucman J, Marineau $\mathrm{C}$, et al: Alteration in a new gene encoding a putative membrane-organizing protein causes neuro-fibromatosis type 2. Nature 363:515-521, 1993

30. Sabha N, Au K, Agnihotri S, Singh S, Mangat R, Guha A, et al: Investigation of the in vitro therapeutic efficacy of nilotinib in immortalized human NF2-null vestibular schwannoma cells. PLoS ONE 7:e39412, 2012

31. Sarbassov DD, Ali SM, Sengupta S, Sheen JH, Hsu PP, Bagley AF, et al: Prolonged rapamycin treatment inhibits mTORC2 assembly and Akt/PKB. Mol Cell 22:159-168, 2006

32. Sarbassov DD, Guertin DA, Ali SM, Sabatini DM: Phosphorylation and regulation of Akt/PKB by the rictor-mTOR complex. Science 307:1098-1101, 2005

33. Shaw RJ, Cantley LC: Ras, PI(3)K and mTOR signalling controls tumour cell growth. Nature 441:424-430, 2006

34. Stemmer-Rachamimov AO, Xu L, Gonzalez-Agosti C, Burwick JA, Pinney D, Beauchamp R, et al: Universal absence of merlin, but not other ERM family members, in schwannomas. Am J Pathol 151:1649-1654, 1997

35. Sturm D, Witt H, Hovestadt V, Khuong-Quang DA, Jones DT, Konermann C, et al: Hotspot mutations in H3F3A and IDH1 define distinct epigenetic and biological subgroups of glioblastoma. Cancer Cell 22:425-437, 2012

36. Torres-Martin M, Lassaletta L, San-Roman-Montero J, De Campos JM, Isla A, Gavilan J, et al: Microarray analysis of gene expression in vestibular schwannomas reveals SPP1/ MET signaling pathway and androgen receptor deregulation. Int J Oncol 42:848-862, 2013

37. Trofatter JA, MacCollin MM, Rutter JL, Murrell JR, Duyao MP, Parry DM, et al: A novel moesin-, ezrin-, radixin-like gene is a candidate for the neurofibromatosis 2 tumor suppressor. Cell 72:791-800, 1993

38. Vanhaesebroeck B, Leevers SJ, Ahmadi K, Timms J, Katso R, Driscoll PC, et al: Synthesis and function of 3-phosphorylated inositol lipids. Annu Rev Biochem 70:535-602, 2001

39. Verhaak RG, Hoadley KA, Purdom E, Wang V, Qi Y, Wilkerson $\mathrm{MD}$, et al: Integrated genomic analysis identifies clinically relevant subtypes of glioblastoma characterized by abnormalities in PDGFRA, IDH1, EGFR, and NF1. Cancer Cell 17:98-110, 2010

40. Wilkerson MD, Hayes DN: ConsensusClusterPlus: a class discovery tool with confidence assessments and item tracking. Bioinformatics 26:1572-1573, 2010

41. Witt H, Mack SC, Ryzhova M, Bender S, Sill M, Isserlin R, et al: Delineation of two clinically and molecularly distinct subgroups of posterior fossa ependymoma. Cancer Cell 20:143157,2011

42. Wong KK, Engelman JA, Cantley LC: Targeting the PI3K signaling pathway in cancer. Curr Opin Genet Dev 20:87-90, 2010

43. Xiao GH, Beeser A, Chernoff J, Testa JR: p21-activated kinase links Rac/Cdc42 signaling to merlin. J Biol Chem 277:883886,2002

44. Zeng Z, Sarbassov DD, Samudio IJ, Yee KW, Munsell MF, Jackson CE, et al: Rapamycin derivatives reduce mTORC2 signaling and inhibit AKT activation in AML. Blood 109:35093512,2007

Manuscript submitted July 15, 2013.

Accepted June 24, 2014.

Please include this information when citing this paper: published online September 23, 2014; DOI: 10.3171/2014.6.JNS131433.

Address correspondence to: Gelareh Zadeh, M.D., Ph.D., Brain Tumor Research Centre, Hospital for Sick Children, Peter Gilgan Centre for Research and Learning, 72 Elm St. Shipping Dock, Rm. 17.9.420, Toronto, ON M5G 0A4, Canada. email: gelareh.zadeh@ uhn.on.ca. 